\title{
ANÁLISE COMPARATIVA ENTRE O CURRÍCULO MUNDIAL PROPOSTO PELA ONU/UNCTAD/ISARE AS UNIVERSIDADES FEDERAIS DO ESTADO DE MINAS GERAIS
}

\author{
A COMPARATIVE ANALYSIS BETWEEN THE WORLD CURRICULUM PROPOSED \\ BY THE UN/UNCTAD/ISAR AND THE \\ CURRICULUMS OF FEDERAL UNIVERSITIES IN MINAS GERAIS
}

Recebido em: 16/12/2011 Aprovado em: 23/02/2012

Avaliado pelo sistema double blind review

Editora Científica: Manolita Correia Lima

\section{LARISSA COUTO CAMPOS lari.couto@hotmail.com \\ SIRLEI LEMES \\ UNIVERSIDADE FEDERAL DE UBERLÂNDIA}

\section{RESUMO}

Devido à globalização, espera-se que um contador seja capaz de atuar além de suas fronteiras nacionais. Para que isso ocorra, a educação deste profissional deve estar de acordo com os anseios do mercado. A ONU (Organização das Nações Unidas), por meio dos setores unctad (United Nations Conference on Trade and Development) e ISAR (International Standards of Accounting and Reporting), formulou um modelo de currículo, que pode ser utilizado como um guia para todas as instituições de ensino de contabilidade, no desenvolvimento de suas grades curriculares. O objetivo desta pesquisa é realizar um estudo comparativo do Currículo Mundial (сM) desenvolvido pela ONU/UNCATD/ISAR com o adotado por universidades mineiras, com o intuito de identificar, quantitativamente, o nível de semelhança entre о см е os currículos analisados. Quatro universidades mineiras foram selecionadas, UFMG, UFSJ, UFU E UFvJM, as quais tiveram suas ementas e programas curriculares comparados com os conteúdos propostos pelo cM. Verificou-se, que, em média, 57,68\% dos conteúdos das universidades analisadas são similares ao currículo proposto pela ONU/UNCTAD/ISAR.

Palavras-chave: currículo mundial; harmonização; ementas.

\section{ABSTRACT}

Currently, due to globalization, it is expected that an accountant be able to act beyond their national borders. For this to occur, this professional education should comply with the whims of the market. The United Nations (UN), through its UNCTAD (United Nations Conference on Trade and Development) and ISAR (International Standards of Accounting and Reporting), issued a model curriculum that can be used as a guide by all education institutions for accounting in developing their curricula. The objective of this research is to conduct a comparative study of the Model Accounting Curriculum (MC) developed by UN/UNCATD/ISAR against those adopted by universities in Minas Gerais, in order to quantitatively identify the level of similarity between the $M C$ and the curricula analyzed. Four universities were selected: UFMG, UFSJ, UFU and UFVJM, and their menus and curricula were compared with the contents proposed by the MC. It was found that, on average, $57.68 \%$ of the contents from the universities examined are similar to the curriculum proposed by the UN/UNCTAD/ISAR.

Keywords: model Aaccounting curriculum; harmonization; menus. 


\section{INTRODUÇÃO}

O fenômeno da globalização, caracterizado pela quebra de barreiras comerciais entre países, o surgimento de blocos econômicos e a internacionalização da economia, tem modificado o mercado mundial em seu todo e afetado as trocas de mercadorias, investimentos, informações e cultura.

O mundo dos negócios sofreu mudanças com os grandes avanços da tecnologia e da globalização. Consequentemente, a contabilidade também se alterou com estas transformações. As práticas e normas contábeis, diferentes entre as diversas economias, têm sido padronizadas e harmonizadas por instituições específicas, como о IASB (International Accounting Standards Board), sucessor do IASC (International Accounting Standards Committee). O intuito é reduzir as diferenças entre os padrões contábeis, aumentar a comparabilidade das informações e, assim, favorecer o comércio e o volume de investimentos nos mercados de capitais. No Brasil, foi criado o Comitê de Pronunciamentos Contábeis ( $\mathrm{CPC}$ ), que visa a harmonizar as normas contábeis brasileiras com as normas instituídas pelo IASB.

É nesse contexto, de mundo globalizado, que o profissional contábil tem uma posição de destaque, uma vez que é ele quem oferece os mecanismos necessários para o controle e a avaliação do desempenho das instituições públicas e privadas, que atuam no mercado globalizado, como afirmam Riccio e Sakata (2004). Além disso, com as novas normas contábeis, espera-se que o contabilista seja capaz de "compreender a magnitude das alterações impostas pela globalização às economias locais" (MAGALHÃES; ANDRADE, 2006, p.2) e, assim, atuar tanto no próprio país como em outro.

Para que esse profissional globalizado exista, Riccio e Sakata (2004) consideram que o ensino dos contadores de todo o mundo deve ser o mais semelhante possível com conhecimentos harmonizados e globalizados, exceto pelas características históricas e culturais de cada país, as quais influenciam o seu conjunto de conhecimento.

Echternacht (2006, p.I8) mostra que alguns organismos internacionais procuram adaptar-se às novas mudanças provocadas pela globalização. 
É o caso do IASB, do IFAC (International Federation of Accountants,) bem como da ONU (Organização das Nações Unidas), esta por meio de setores como a UnCTAd (United Nations Conference on Trade and Development), e o ISAR (International Standards of Accounting and Reporting). Em suas atuações, esses órgãos buscam, além da aprovação e adoção das Normas Internacionais, a formulação de tratamento para aqueles que colocarão tais normas em prática. Especificamente a ONU/UNCTAD/ISAR elaborou uma sugestão de currículo a que se pode recorrer como guia para todas as instituições de ensino de contabilidade no desenvolvimento de suas grades curriculares. Este currículo é o foco da presente pesquisa.

Diante de todas estas mudanças provenientes da globalização, que afetaram a carreira dos contadores, a harmonização não apenas das normas contábeis, mas também do ensino, se mostra pertinente nos dias atuais. Portanto, os estudos das propostas de unificação dos currículos dos cursos de Ciências Contábeis, aprovadas pela ONU/UnCTAD/ISAR, e de seus impactos nas universidades brasileiras, mostram-se relevantes para o desenvolvimento do ensino contábil.

Ao contrário de outros trabalhos sobre o assunto, que pesquisaram as disciplinas semelhantes entre CM e currículos de outras instituições, como Riccio e Sakata (2004); Erfurth e Domingues (2008); Magalhães e Andrade (2006); Czesnat, Cunha e Domingues (2009) e Segantini e outros (2010), analisaram-se, neste estudo, todos os conteúdos propostos pelo CM, baseados no "Modelo Revisado de Plano de Estudos de Contabilidade", o TD 2I, comparando-o com todos os conteúdos propostos pelas ementas e/ ou programas curriculares das universidades da amostra. As disciplinas optativas também foram consideradas, mas separadamente, comparandoas com o quarto bloco, optativo, do CM denominado, neste documento, por Nível Optativo de Contabilidade, Finanças e Conhecimentos Afins (avançados).

Desse modo, a presente pesquisa propõe responder à seguinte questão: qual o indice de similaridade entre os programas curriculares da Universidade Federal de Minas Gerais (UFMG), Universidade Federal de São João Del Rei (UFSJ), Universidade Federal de Uberlândia (UFu) e Universidade Federal dos Vales do 
Jequitinhonha e Murici (UFVJM) em relação ao curriculo mundial proposto pela ONU/UNCTAD/ISAR?

Nesse sentido, o objetivo geral deste trabalho é fazer um estudo comparativo do Currículo Mundial (CM), desenvolvido pela ONU/UnCATD/ ISAR, com o adotado por universidades mineiras, com o intuito de identificar, quantitativamente, o nível de semelhança entre o см е os currículos estudados.

Os objetivos específicos são: identificar os principais aspectos do см; identificar os itens de comparação com os currículos das universidades federais mineiras e calcular, para cada universidade, um índice que proporcione o grau de similaridade entre os conteúdos identificados nas Instituições de Ensino com o cм.

O índice foi calculado por meio da divisão entre a soma de conteúdos, similares aos propostos pelo См, das universidades da amostra, pelo total de conteúdos identificados nelas.

A presente pesquisa foi estruturada em cinco seções: a primeira traz os aspectos introdutórios da pesquisa; a segunda contempla a fundamentação teórica, levantando as principais informações e conceitos que contribuem para o entendimento do assunto; na terceira seção, são apresentados os aspectos metodológicos e descritas as universidades e disciplinas analisadas; na quarta seção, são tecidas as conclusões dos resultados; a quinta seção apresenta os resultados de pesquisas anteriores, que também realizaram análises comparativas do см com outras universidades e, por fim, na sexta seção são feitas as considerações finais sobre a pesquisa. 


\section{REFERENCIAL TEÓRICO}

Neste tópico, serão abordados o currículo, seus conceitos e importância perante o processo de ensino-aprendizagem; o currículo do curso de Ciências Contábeis, segundo as resoluções e exigências do MEc; e as propostas da UNCTAD na elaboração de um currículo mundial, bem como as pesquisas anteriores que tiveram como tema o currículo do curso de Ciências Contábeis.

\section{O CURRÍCULO}

Um assunto muito discutido nos últimos anos, principalmente pelos profissionais envolvidos com o processo de ensino e aprendizagem, é o "currículo" (PELEIAS, 2006). Estes profissionais procuram compreender de forma crítica a educação e como os padrões predefinidos influenciam uma comunidade educacional. De acordo com Lima, Lemos e Anaya (2006 p. 147):

o termo currículo provém da palavra latina currere, que se refere à carreira, a um percurso que deve ser realizado. Neste contexto, a escolaridade, via conteúdos expressos no currículo, é o meio pelo qual o aluno se apropria dos conteúdos significativos, de forma progressiva, galgando degraus rumo à completa escolarização.

Dutra (2003) conceitua currículo como a metodologia utilizada pela escola para transferir o conhecimento funcional ao educando. Já, Messick, Paixão e Bastos (1980, p.9) consideram que um leigo definiria currículo como "relação de matérias estudadas pelos alunos de determinado nível de ensino". Apesar de simplista, para estes autores, esta seria uma das melhores definições para o termo.

Seguindo o mesmo raciocínio, Tcheou (2002, apud PELEIAS, 2006) considera que currículo é:

o conjunto de disciplinas, organizadas em uma sequência lógica de conteúdos, que busca atender às necessidades e às expectativas da sociedade em relação ao indivíduo a ser formado por ela.

Do mesmo modo, Mulatinho (2007) afirma que a função do currículo não é apenas a formação técnico-científica, a qual possui caráter estritamente 
prático, mas sim a construção de conhecimentos resultantes que refletem as relações e as necessidades sociais.

De acordo com Peleias (2006), presume-se que os currículos guiem o processo de ensino e aprendizagem, pois abordam as necessidades básicas para a formação profissional do aluno. Assim, diversos elementos influenciam a estrutura de um currículo, como: demandas das políticas cultural, social, econômica e educacional; grupos dominantes; histórias de currículos anteriores; princípios psicológicos; avanços tecnológicos; pesquisa de área; conjunturas econômicas; concepções que norteiam o âmbito escolar, entre outros.

Desse modo, um currículo deve acompanhar as mudanças que ocorrem na sociedade, sejam mudanças na ordem social, econômica ou cultural. Além disso, Mulatinho (2007) afirma que a formação do aluno deve acompanhar as mudanças da ciência, uma vez que a evolução científica traz quebras de paradigmas, surgimento de novos conhecimentos, novos campos de atuação, e assim por diante.

Ao utilizar essa ideia no ensino de contabilidade e ao analisar todas as mudanças acarretadas pela globalização que afetaram o mercado contábil, conclui-se que o ensino do futuro contador deve ser reavaliado constantemente. Estas transformações refletem-se diretamente no mercado de trabalho e determinam o que a sociedade espera de um contador qualificado. Conforme Sacristán (2000, p.32):

o currículo é um ponto central na melhora da qualidade do ensino, na mudança das condições da prática, no aperfeiçoamento dos professores, na renovação da instituição escolar em geral e nos projetos de inovação dos centros escolares. Por isso, o estudo do currículo e a análise de possíveis mudanças têm efeito positivo na manutenção e qualidade do ensino.

\section{CURRÍCULO DO CURSO DE CIÊNCIAS CONTÁBEIS}

No Brasil, o MEC estabelece as exigências necessárias referentes para que uma instituição de ensino superior ofereça qualquer curso, e define que a qualificação de um contador dar-se-á por meio de um curso de graduação, que conferirá o grau de bacharel em Ciências Contábeis e cumprirá os 
mínimos de conteúdo e de duração.

A Resolução n. 3, de 5/1o/1992, do extinto Conselho Federal de Educação (CFE), fixava os mínimos de conteúdos e a duração do curso de graduação em Ciências Contábeis. Atualmente, a Resolução do Conselho Nacional de Educação CNE/CES n. Io/2004 guia o projeto pedagógico das novas turmas. Esta resolução estabelece as diretrizes curriculares a serem observadas pelas instituições de ensino, ao elaborarem a organização curricular do curso de contabilidade, como os conteúdos, as recomendações e sugestões de conhecimentos, a carga horária e a duração do curso. Além disso, expressa o perfil desejado do formado, as competências e habilidades requeridas.

Segundo Dutra (2003, p. 62), as normas do MEC fornecem diretrizes mínimas, pois a universidade possui autonomia para estabelecer as grades curriculares para seus cursos. Do mesmo modo, Pires e Ott (2008, p.7) concluem que:

as determinações da Resolução CNE/CES n. Io/2004 são amplas e flexíveis o que significa que cabe a cada IEs definir, por exemplo, quais as disciplinas a serem ministradas e o número de horas-aula destinadas a cada conteúdo, desde que as diretrizes estabelecidas sejam observadas, ou seja, desde que os conteúdos curriculares sejam contemplados.

Os autores Pires e Ott (2008) ainda asseveram que as necessidades do mercado, referentes às qualificações exigidas do futuro profissional contábil, irão guiar as IES ao planejarem seus currículos e preparar os alunos a fim de satisfazer as demandas do mercado de trabalho.

A UnCTAD também expôs um plano de estudo que visa a auxiliar as instituições de ensino a construírem o currículo para o Curso de Ciências Contábeis. Este plano tem como finalidade propor as questões técnicas que um aluno deve dominar para ser um contador profissional. Conforme Mulatinho (2007, p. 32), este plano de estudos evidencia:

a importância de se desenvolver um currículo que aborda disciplinas de conhecimentos gerais e técnicos, bem como desenvolver habilidades e consciência profissional, com base em avaliações de competência e da educação continuada, e se estes estão concatenados com as prerrogativas de um mundo altamente interligado. 
O plano de estudos sugerido pela UNCTAD será estudado de forma mais detalhada na seção a seguir.

\section{UNCTAD E O "PLANO MUNDIAL DE ESTUDOS PARA FORMAÇÃO DE CONTADORES”}

A UNCTAD é um órgão ligado à ONU o qual promove a integração favorável ao crescimento dos países em desenvolvimento na economia mundial. Esta instituição trabalha com as questões enfrentadas por essas economias para sua inserção no comércio internacional.

A UnCTAD possui um grupo de especialistas em padrões contábeis internacionais, denominado Intergovernmental Working Group of Experts on International Standards of Accounting and Reporting (ISAR). Este grupo auxilia países em desenvolvimento a aplicar as melhores práticas de transparência empresarial e contábil, a fim de facilitar os fluxos de investimento e desenvolvimento econômico (UNCTAD, 20IO).

O grupo de trabalho ISAR ponderou que era necessário preparar um programa mundial que servisse de referência e permitisse reduzir o tempo e o custo de negociar acordos de reconhecimentos mútuos e, com isso, aumentar o comércio externo de serviços de contabilidade. Como consequência, O ISAR pediu à UNCTAD que prosseguisse seus trabalhos sobre a elaboração de um programa mundial de estudos e outros requisitos para contadores em cooperação com outros organismos pertinentes, como a Federação Internacional de Contadores, a Sociedade Árabe de Contadores Públicos e a Associação de Contadores Públicos Colegiados.

Em 1999, o ISAR realizou sua I6 ${ }^{\text {a }}$ Sessão em Genebra, Suíça, e, desta reunião, o órgão divulgou dois documentos referentes à elaboração de um currículo mundial de estudos em contabilidade. O primeiro documento foi O TD/B/COM.2/ISAR/5 (TD 5), intitulado de Guideline on National Requirements for the Qualification of Professional Accountants, que consiste em um programa mundial de estudos de contabilidade e outras normas e requisitos de qualificação para os profissionais de contabilidade. Já o segundo documento, о TD/в/COM.2/ISAR/6 (TD 6), denominado de Global Curriculum for the Professional Education of Professional Accountants, consiste 
em um programa de estudos mais detalhado. Este programa apresenta sugestões de conhecimentos e conteúdos de disciplinas de contabilidade e auditoria.

A proposta desses projetos é estabelecer uma referência para as qualificações nacionais e permitir que os alunos de contabilidade possam estar aptos a atuar em um contexto de uma economia global. As diretrizes foram elaboradas no interesse da comunidade internacional em seu todo, com o intuito de promover a harmonização mundial dos requisitos de qualificação dos profissionais da contabilidade. Nota-se que a finalidade dessa iniciativa não é estabelecer uma "qualificação global”, já que as qualificações se obtêm, geralmente, em nível nacional.

O TD 5 ressalta que o Currículo Mundial é simplesmente um ponto de partida para os países que desejam harmonizar seu sistema educativo com os requisitos mundiais. Cada país deve, baseando-se nesse currículo, elaborar seus próprios programas, determinar o tempo que se dedicará a cada módulo e adaptar o conteúdo às suas necessidades nacionais.

Em 2003, o programa mundial de estudos de contabilidade foi revisado pelo ISAR/UNCTAD, o qual formulou um novo documento, о тD/в/СОм.2/ ISAR/2I (TD 2I), intitulado "Modelo revisado de plano de estudos de contabilidade" (Revised Model Accounting Curriculum). Segundo Pereira et al. (2005, p.2), este estudo foi resultado de "observações quanto às restrições e deficiências de aplicação prática do primeiro modelo", mantendo as principais diretrizes do TD 5 e do TD 6.

No modelo revisado do plano de estudos de contabilidade, O TD 2I, O ISAR dividiu os conhecimentos necessários para um curso de contabilidade em quatro grandes blocos, e, em cada bloco, indicou módulos específicos para os estudos. No modelo anterior, o TD 6, os conhecimentos eram divididos em apenas três blocos de conhecimento: Conhecimentos da organização e atividade comercial; Tecnologia da informação; e Conhecimentos Básicos de Contabilidade e afins. No novo modelo, um quarto bloco foi acrescentado, e refere-se ao nível optativo (avançado) de Contabilidade, Finanças e Conhecimentos Afins. O Quadro I, a seguir, exibe os blocos de conhecimento sugeridos pela ONU/ISAR/UNCTAD no modelo revisado e os 
módulos que compõem cada bloco:

Quadro 1 Blocos de conhecimento sugeridos pela ONU/ISAR/UNCTAD

\begin{tabular}{|c|c|c|c|}
\hline $\begin{array}{l}1 \text { Conhecimentos } \\
\text { da Organização e } \\
\text { Atividade Comercial }\end{array}$ & $\begin{array}{l}2 \text { Tecnologia da } \\
\text { Informação }\end{array}$ & $\begin{array}{l}3 \text { Conhecimentos } \\
\text { Básicos de } \\
\text { Contabilidade e afins }\end{array}$ & $\begin{array}{l}4 \text { Nível Optativo de } \\
\text { Cont., Finanças e } \\
\text { Conhecimentos Afins } \\
\text { (avançados) }\end{array}$ \\
\hline 1.1 Economia & \multirow[t]{11}{*}{$\begin{array}{l}2.1 \text { Tecnologia da } \\
\text { informação }\end{array}$} & 3.1 Cont. Básica & $\begin{array}{l}\text { 4.1 Apresentações de } \\
\text { relatórios financeiros } \\
\text { e Cont. nível avançado } \\
\text { para empresas especí- } \\
\text { ficas }\end{array}$ \\
\hline $\begin{array}{l}\text { 1.2 Método quantita- } \\
\text { tivo e estatístico para } \\
\text { administração }\end{array}$ & & 3.2 Cont. Financeira & $\begin{array}{l}4.2 \text { Cont. Gerencial } \\
\text { avançada }\end{array}$ \\
\hline $\begin{array}{l}1.3 \text { Políticas gerais das } \\
\text { empresas, estrutura } \\
\text { organizacional e com- } \\
\text { portamento das orga- } \\
\text { nizações }\end{array}$ & & $\begin{array}{l}\text { 3.3 Cont. Financeira } \\
\text { Avançada }\end{array}$ & $\begin{array}{l}4.3 \text { Cont. Tributária } \\
\text { Avançada }\end{array}$ \\
\hline $\begin{array}{l}\text { 1.4 Funções e práticas } \\
\text { de gestão e adminis- } \\
\text { tração das atividades }\end{array}$ & & $\begin{array}{l}\text { 3.4 Cont. Gerencial- } \\
\text {-básico }\end{array}$ & $\begin{array}{l}\text { 4.4 Direito comercial } \\
\text { avançado }\end{array}$ \\
\hline 1.5 Marketing & & 3.5 Cont. Tributária & 4.5 Auditoria avançada \\
\hline \multirow[t]{6}{*}{$\begin{array}{l}1.6 \text { Comércio Interna- } \\
\text { cional }\end{array}$} & & $\begin{array}{l}3.6 \text { Sist. Informação } \\
\text { aplicada à Cont. }\end{array}$ & $\begin{array}{l}\text { 4.6 Financiamento } \\
\text { Comercial avançado e } \\
\text { Gestão financeira }\end{array}$ \\
\hline & & 3.7 Direito Comercial & \multirow[t]{5}{*}{ 4.7 Estágio } \\
\hline & & $\begin{array}{l}\text { 3.8 Princípios funda- } \\
\text { mentais da segurança } \\
\text { e auditoria }\end{array}$ & \\
\hline & & $\begin{array}{l}\text { 3.9 Financiamento } \\
\text { comercial e Gestão } \\
\text { financeira }\end{array}$ & \\
\hline & & $\begin{array}{l}3.10 \text { Integração dos } \\
\text { conhecimentos }\end{array}$ & \\
\hline & & $\begin{array}{l}3.10 \text { Integração dos } \\
\text { conhecimentos }\end{array}$ & \\
\hline
\end{tabular}

Fonte TD/B/COM.2/ISAR/21 (2003).

O plano do Currículo Mundial especifica, além dos blocos de conhecimentos 
e módulos, os objetivos que se esperam de cada módulo e os principais conteúdos que cada módulo deve conter.

\section{PESQUISAS ANTERIORES}

Cavalcante et al. (20II) afirmam que no cenário internacional a reforma de currículos de Contabilidade nas universidades tem sido muito discutido. Esses autores destacam os trabalhos de Preobragenskaya e McGee (2002) e Kavanagh e Drennah (2007). O estudo de Preobragenskaya e McGee (2002) descreve como a Armênia e a Bósnia realizaram uma reforma curricular nos cursos de Ciências Contábeis, baseando-se nas recomendações da Association of Chartered Certified Accountants (ACCA), que fundamentou suas orientações no CM sugerido pela ONU/UNCTAD/ISAR e recomendam que uma reforma semelhante seja realizada na Rússia.

Já a pesquisa de Kavanagh e Drennah (2007) examinou as percepções e expectativas dos estudantes e do mercado de trabalho da Austrália referente às competências e habilidades exigidas de um profissional contábil. Esse estudo verificou que diversas habilidades, como a comunicação oral, consciência empresarial e trabalho em equipe, não são suficientemente desenvolvidas em programas curriculares nas universidades.

As habilidades necessárias para o ensino de contabilidade, conforme a percepção dos profissionais de contabilidade, educadores e estudantes, também foram objeto de estudo de Lin, Xiong e Liu, (2005). Os resultados desse estudo revelaram que a base de conhecimento do ensino de contabilidade na China ainda é muito estreita e que alguns conhecimentos não são abordados de maneira satisfatória. Além disso, o desenvolvimento de habilidades continua sendo uma área relativamente fraca, que deve ser reforçada de forma significativa na educação contábil chinesa.

Ashcroft, Chevis e Smith (2008) focaram sua pesquisa no papel fundamental que a Contabilidade Internacional exerce no currículo do curso de Ciências Contábeis. Este estudo analisou diversos temas internacionais de contabilidade por meio de uma pesquisa com membros da American Accounting Association's International Accounting Section. Os resultados encontrados, segundo os autores, são úteis para que IES 
integrem questões internacionais em seus cursos de contabilidade.

No Brasil, as reformas curriculares nos cursos de contabilidade também têm sido pesquisadas. O см, por exemplo, é objeto de estudo de algumas dessas pesquisas, que propõem realizar uma análise comparativa entre as propostas do $\mathrm{CM}$ e as grades curriculares adotadas por diferentes universidades, buscando avaliar a similaridade entre os currículos coletados e a proposta da ONU/UNCTAD/ISAR. Em contrapartida, esses estudos diferem entre si ao apresentarem amostras e metodologias distintas umas das outras.

O Quadro 2, a seguir, destaca alguns desses estudos, apresentando os objetivos, a metodologia e os principais resultados coletados em cada pesquisa.

Quadro 2 Artigos publicados sobre análises comparativas com o cM

\begin{tabular}{|c|c|c|c|c|}
\hline Autores & & Objetivos & $\begin{array}{l}\text { Aspectos } \\
\text { Metodológicos }\end{array}$ & Principais Resultados \\
\hline $\begin{array}{l}\text { Riccio } \\
\text { Sakata } \\
(2004)\end{array}$ & & $\begin{array}{l}\text { Comparar as grades curri- } \\
\text { culares de universidades } \\
\text { portuguesas e brasileiras, } \\
\text { com os blocos de conhe- } \\
\text { cimentos sugeridos pelo } \\
\text { CM }\end{array}$ & $\begin{array}{l}\text { Pesquisa exploratória; } \\
\text {-Amostra: } 25 \text { universida- } \\
\text { des portuguesas e } 25 \\
\text { brasileiras (públicas e } \\
\text { privadas); } \\
\text { - O estudo categoriza as } \\
\text { disciplinas das grades } \\
\text { curriculares de cada uni- } \\
\text { versidade de acordo com } \\
\text { os blocos de conheci- } \\
\text { mento do CM }\end{array}$ & $\begin{array}{l}\text {-Universidades Brasileiras } \\
\text { mais próximas do CM em } \\
\text { relação às Portuguesas; } \\
\text {-Bloco de conhecimentos } \\
\text { administrativos e organi- } \\
\text { zacionais, nos dois países, } \\
\text { é o que apresentou maior } \\
\text { aproximação. O que mais } \\
\text { se distanciou foi o Bloco } \\
\text { de Conhecimentos Gerais } \\
\text { (adaptado pelos autores); } \\
\text {-Baixa quantidade de dis- } \\
\text { ciplinas de Tecnologia da } \\
\text { Informação (TI) }\end{array}$ \\
\hline
\end{tabular}




\begin{tabular}{|c|c|c|c|}
\hline Autores & Objetivos & $\begin{array}{l}\text { Aspectos } \\
\text { Metodológicos }\end{array}$ & Principais Resultados \\
\hline $\begin{array}{l}\text { Magalhães } \\
\text { e Andrade } \\
(2006)\end{array}$ & $\begin{array}{l}\text { Diagnosticar, caracterizar } \\
\text { e compreender o grau de } \\
\text { aderência dos cursos de } \\
\text { Ciências Contábeis do } \\
\text { Estado do Piauí às diretri- } \\
\text { zes sugeridas pela ONU/ } \\
\text { UNCTAD/ISAR por meio } \\
\text { do CM }\end{array}$ & $\begin{array}{l}\text {-Pesquisa bibliográfica e } \\
\text { exploratória; } \\
\text {-Amostra: } 20 \text { cursos de } \\
\text { Ciências Contábeis do } \\
\text { Estado do Piauí, aprova- } \\
\text { dos pelo MEC; } \\
\text { - As disciplinas foram cate- } \\
\text { gorizadas conforme os } \\
\text { blocos de conhecimentos } \\
\text { e comparadas, por meio } \\
\text { da nomenclatura, com as } \\
\text { disciplinas do CM; } \\
\text {-As disciplinas receberam } \\
\text { valores "1" ou "0" con- } \\
\text { forme se aproximavam } \\
\text { ou não das recomenda- } \\
\text { ções do CM }\end{array}$ & $\begin{array}{l}\text {-Os currículos aplicados } \\
\text { no Piauí não apresentam, } \\
\text { entre si, grandes variações } \\
\text { em relação à proposta da } \\
\text { - ONU/UNCTAD/ISAR; } \\
\text {-40\%, em média, das disci- } \\
\text { - plinas sugeridas pelo CM } \\
\text { não encontram correspon- } \\
\text { dentes nos currículos sele- } \\
\text { cionados; } \\
\text {-Principal diferença entre os } \\
\text { currículos: bloco de Conta- } \\
\text { bilidade e Assuntos Afins; } \\
\text {-Pouca oferta de disciplina } \\
\text { na área de TI; } \\
\text { - -Ausência de disciplinas } \\
\text { relacionadas a negócios e } \\
\text { temas internacionais }\end{array}$ \\
\hline $\begin{array}{l}\text { Erfurth e } \\
\text { Domingues } \\
(2008)\end{array}$ & $\begin{array}{l}\text { Comparar as estruturas } \\
\text { curriculares do curso de } \\
\text { ciências contábeis da } \\
\text { Universidade de Buenos } \\
\text { Aires com o CM }\end{array}$ & $\begin{array}{l}\text {-Pesquisa exploratória, } \\
\text { com método qualitativo } \\
\text { e com abordagem docu- } \\
\text { mental em fontes primá- } \\
\text { rias; } \\
\text {-Amostra: Universidade de } \\
\text { Buenos Aires; } \\
\text {-Disciplinas foram separa- } \\
\text { das por bloco de conhe- } \\
\text { cimentos sugeridos pelo } \\
\text { CM }\end{array}$ & $\begin{array}{l}\text {-Há uma aproximação entre } \\
\text { as estruturas curriculares; } \\
\text { - Falta desenvolver mais } \\
\text { - disciplinas voltadas à TI, à } \\
\text { contabilidade internacional, } \\
\text { e à contabilidade gerencial }\end{array}$ \\
\hline
\end{tabular}




\begin{tabular}{|c|c|c|c|}
\hline Autores & Objetivos & $\begin{array}{l}\text { Aspectos } \\
\text { Metodológicos }\end{array}$ & Principais Resultados \\
\hline $\begin{array}{l}\text { Czesnat, } \\
\text { Cunha e } \\
\text { Domingues } \\
(2009)\end{array}$ & $\begin{array}{l}\text { Avaliar os currículos dos } \\
\text { cursos de Ciências Con- } \\
\text { tábeis de Santa Catarina } \\
\text { comparando-os com a } \\
\text { proposta do CM }\end{array}$ & $\begin{array}{l}\text {-Pesquisa descritiva, docu- } \\
\text { mental e bibliográfica; } \\
\text {-Amostra: } 12 \text { universida- } \\
\text { des de Santa Catarina, } \\
\text { listadas pelo MEC; } \\
\text {-Na análise dos dados } \\
\text { foram empregados cri- } \\
\text { térios de similaridade e } \\
\text { proximidade para com- } \\
\text { parar as disciplinas que } \\
\text { compõem os currículos } \\
\text { das universidades pes- } \\
\text { quisadas às disciplinas } \\
\text { sugeridas pelo CM }\end{array}$ & $\begin{array}{l}\text {-Os currículos dos cursos } \\
\text { pesquisados possuem um } \\
\text { alto grau de similaridade } \\
\text { com o CM; } \\
\text { - Maior similaridade com o } \\
\text { bloco Conhecimentos de } \\
\text { contabilidade; } \\
\text {-Disciplinas do bloco de TI } \\
\text { são as menos contempla- } \\
\text { das pelos currículos anali- } \\
\text { sados; } \\
\text {-As instituições selecionadas } \\
\text { estão adaptando seus cur- } \\
\text { rículos ao CM no que tange } \\
\text { às disciplinas voltadas ao } \\
\text { mercado nacional; } \\
\text {-Referente ao mercado inter- } \\
\text { nacional, a similaridade é } \\
\text { mínima }\end{array}$ \\
\hline $\begin{array}{l}\text { Segantini et } \\
\text { al. (2010) }\end{array}$ & $\begin{array}{l}\text { Analisar e comparar a } \\
\text { adequação dos currícu- } \\
\text { los dos cursos de ciências } \\
\text { contábeis do MERCOSUL } \\
\text { com o CM proposto pela } \\
\text { ONU/UNCTAD/ISAR }\end{array}$ & $\begin{array}{l}\text {-Pesquisa descritiva docu- } \\
\text { mental, bibliográfica e } \\
\text { qualitativa; } \\
\text {-Amostra: quatro universi- } \\
\text { dades do MERCOSUL; } \\
\text {-Compararam-se as maté- } \\
\text { rias que compõem os cur- } \\
\text { rículos selecionados com } \\
\text { as matérias sugeridas } \\
\text { pelo CM }\end{array}$ & $\begin{array}{l}\text { - Bloco com maior seme- } \\
\text { Ihança: conhecimento } \\
\text { administrativo e organiza- } \\
\text { cional; } \\
\text { - Maior distanciamento do } \\
\text { CM: disciplinas sobre TI }\end{array}$ \\
\hline $\begin{array}{l}\text { Cavalcante } \\
\text { et al. (2011) }\end{array}$ & $\begin{array}{l}\text { Investigar a adequação } \\
\text { dos currículos adotados } \\
\text { pelos cursos de Ciências } \\
\text { Contábeis nas universi- } \\
\text { dades federais brasileiras } \\
\text { ao CM }\end{array}$ & $\begin{array}{l}\text {-Pesquisa com abordagem } \\
\text { hipotético-dedutiva, de } \\
\text { cunho quantitativo; } \\
\text { - Amostra: } 27 \text { universida- } \\
\text { des federais brasileiras } \\
\text { que ofertam graduação } \\
\text { em Ciências Contábeis; } \\
\text {-Ferramentas estatísticas: } \\
\text { correlação de Spearman }\end{array}$ & $\begin{array}{l}\text {-Não há correlação entre a } \\
\text { adequação pelas universi- } \\
\text { dades federais brasileiras } \\
\text { ao CM e o conceito Enade } \\
\text { de 2006; } \\
\text { - Muitas disciplinas oferta- } \\
\text { das pelas universidades } \\
\text { federais não encontram } \\
\text { correspondentes no CM, } \\
\text { com destaque para Perícia } \\
\text { Contábil }\end{array}$ \\
\hline
\end{tabular}




\begin{tabular}{|c|c|c|c|}
\hline Autores & Objetivos & $\begin{array}{l}\text { Aspectos } \\
\text { Metodológicos }\end{array}$ & Principais Resultados \\
\hline $\begin{array}{l}\text { Zonatto, } \\
\text { Dani e } \\
\text { Domingues } \\
(2011)\end{array}$ & $\begin{array}{l}\text { Averiguar se os currículos } \\
\text { dos Cursos de Graduação } \\
\text { presenciais em Ciências } \\
\text { Contábeis, das IES lista- } \\
\text { das pelo MEC, localizadas } \\
\text { no Estado do Rio Grande } \\
\text { do Sul (RS), estão alinha- } \\
\text { dos ao currículo mundial } \\
\text { proposto pela ONU/UNC- } \\
\text { TAD/ISAR }\end{array}$ & $\begin{array}{l}\text {-Pesquisa descritiva com } \\
\text { abordagem qualitativa } \\
\text { dos dados; } \\
\text { - Amostra: } 51 \text { IES listadas } \\
\text { pelo MEC do Rio Grande } \\
\text { do Sul (RS), que oferecem } \\
\text { Cursos presenciais em } \\
\text { Ciências Contábeis; } \\
\text { - Período da coleta de } \\
\text { dados: entre os meses } \\
\text { de outubro e novembro } \\
\text { de } 2010 ; \\
\text { - Foram comparadas as } \\
\text { disciplinas das univer- } \\
\text { sidades com o CM, por } \\
\text { meio de análise por simi- } \\
\text { laridade }\end{array}$ & $\begin{array}{l}\text {-Alta aderência em relação } \\
\text { aos currículos analisados } \\
\text { ao CM; } \\
\text { - Instituições pesquisadas } \\
\text { possuem seus currículos } \\
\text { alinhados às recomenda- } \\
\text { ções propostas pela ONU/ } \\
\text { UNCTAD/ISAR; } \\
\text {-Não há disseminação da } \\
\text { disciplina de Contabilidade } \\
\text { Internacional nas institui- } \\
\text { ções pesquisadas }\end{array}$ \\
\hline $\begin{array}{l}\text { Santos, } \\
\text { Domingues } \\
\text { e Ribeiro } \\
\text { (2011) }\end{array}$ & $\begin{array}{l}\text { Verificar o nível de ade- } \\
\text { rência das disciplinas do } \\
\text { Curso de Ciências Con- } \\
\text { tábeis das instituições } \\
\text { de ensino do Estado do } \\
\text { Paraná, listadas MEC, em } \\
\text { relação às disciplinas } \\
\text { sugeridas pelo CM }\end{array}$ & $\begin{array}{l}\text {-Pesquisa Descritiva com } \\
\text { abordagem quantitativa; } \\
\text {-Amostra: } 72 \text { IES do Paraná } \\
\text { (ensino à distância e } \\
\text { ensino presencial) sendo } \\
57 \text { privadas e } 15 \text { públicas; } \\
\text { - Foram comparadas as } \\
\text { disciplinas das IES com o } \\
\text { CM, por meio de análise } \\
\text { por similaridade }\end{array}$ & $\begin{array}{l}\text { - Ao considerar a análise } \\
\text { total de Blocos de Conheci- } \\
\text { mentos do CM: as Matrizes } \\
\text { Curriculares paranaenses } \\
\text { apresentam resultados } \\
\text { simétricos em comparação } \\
\text { ao CM; } \\
\text { - Se a análise ocorrer em blo- } \\
\text { cos individuais: verifica-se } \\
\text { um desequilíbrio de ade- } \\
\text { rência entre os mesmos; } \\
\text { - Menor percentual de simi- } \\
\text { laridade: bloco de TI }\end{array}$ \\
\hline
\end{tabular}


Apesar de as amostras utilizadas variarem entre as pesquisas, foi unânime a constatação de que existe uma relação, e logo, similaridade, entre a proposta internacional e os currículos avaliados, ainda que os pontos semelhantes sejam diferentes de uma ies para a outra. Contudo, nota-se que em todas as análises comparativas foi detectada a baixa quantidade de disciplinas da área de Tecnologia da Informação nas instituições analisadas, se comparadas com as recomendações do CM.

Observa-se também que todos os estudos apresentados no Quadro 2 se assemelham por compararem apenas as disciplinas das IEs e do CM, e não os conteúdos propostos em cada um delas. 


\section{ASPECTOS METODOLÓGICOS}

\section{MÉTODO E TIPOLOGIA DE PESQUISA}

A presente pesquisa contempla o método de pesquisa bibliográfica e documental. Bibliográfica porque recorre a referenciais teóricos já publicados em livros, artigos, teses (BEUREN, 2006, p.89), e pelos quais se busca aumentar o contato dos autores com o assunto a ser trabalhado (LAKATOS; MARCONI, 200I). Documental, por basear-se em documentos oficiais elaborados pela ONU/UNCTAD/ISAR, materiais que ainda não receberam tratamento analítico (GIL, 2006).

Os procedimentos, quanto aos objetivos, foram delineados pela pesquisa descritiva. Segundo Andrade (2002, apud BEUREN, 2006, p.8I), a pesquisa descritiva "preocupa-se em observar os fatos, registrá-los, analisá-los, classificá-los e interpretá-los” de forma que o pesquisador não interfira nos resultados.

Por fim, quanto à metodologia empregada na abordagem do problema, a pesquisa se assinala como quantitativa. Conforme Beuren (2006, p. 92), "a abordagem quantitativa caracteriza-se pelo emprego de instrumentos estatísticos, tanto na coleta quanto no tratamento dos dados”.

No procedimento de coleta de dados, aplicou-se o método de documentação indireta, por meio de fontes secundárias. Utilizou-se de currículos e outros documentos pertinentes à pesquisa, disponibilizados em sítios eletrônicos das Universidades e dos órgãos relacionados.

Além disso, as instituições de ensino, que não disponibilizam seus programas curriculares nos sítios eletrônicos, foram contatadas, por email, para troca de informações. Apenas as Universidades que forneceram seus programas foram analisadas.

\section{CARACTERÍSTICAS DO MÉTODO DE COLETA DE DADOS}

Foram selecionadas, para a pesquisa, apenas as universidades que disponibilizaram suas ementas ou programas curriculares fossem por seus sítios, na data da pesquisa, fossem por contato preestabelecido. As 
instituições federais selecionadas foram: UFMG, UFSJ, UFU E UFvJM, num total de seis universidades federais de Minas Gerais, que contemplam o curso de Ciências Contábeis.

Para o tratamento de dados, empregou-se o índice de disclosure utilizado por Malaquias (2008) e Gubiani et al. (2010), adaptado para este estudo. Seguindo essa técnica, uma determinada pontuação foi fornecida para cada conteúdo presente nas ementas ou nos programas curriculares das IES selecionadas. O somatório da pontuação alcançada por determinada universidade foi dividido pelo total de conteúdos que essa mesma IES apresentou. Esta divisão permitiu calcular o índice em percentual.

Para calcular o valor do índice, foi necessário, antes, separar e enumerar todos os conteúdos programáticos sugeridos pelo см por meio do documento revisado TD 2I. Estes conteúdos foram divididos entre "blocos de conhecimento", sugeridos pelo cM, conforme o Quadro 3.

Quadro 3 Blocos de Conhecimento sugeridos no TD 21

\begin{tabular}{|ll|}
\hline Bloco 1 & Conhecimentos da Organização e Atividade Comercial \\
\hline Bloco 2 & Tecnologia da Informação \\
\hline Bloco 3 & Conhecimentos Básicos de Contabilidade e afins \\
\hline Bloco 4 & Nível Optativo de Contabilidade Finanças e Conhecimentos Afins (avançados) \\
\hline
\end{tabular}

Fonte TD/B/COM.2/ISAR/21 (2003).

No total, foram identificados 659 conteúdos obrigatórios, entre os três primeiros blocos, e 157 conteúdos no bloco optativo. Cada conteúdo recebeu uma numeração para que servisse de referência nas análises seguintes.

De forma similar, os conteúdos, retirados das ementas ou programas curriculares oferecidos pelas universidades mineiras da amostra, foram separados e enumerados em planilhas específicas. Além de serem analisados e confrontados com os conteúdos sugeridos pelo cм, cada conteúdo recebeu uma pontuação. Valor "I" para os conteúdos propostos pelo CM; e valor "o" para os que não foram propostos.

O critério de avaliação utilizado para a análise dos conteúdos consistiu 
em: observar os conteúdos semelhantes por meio da nomenclatura ou observar o contexto a que cada conteúdo se refere (apesar da nomenclatura diferente, o contexto é o mesmo). Se, pelo menos, um dos dois critérios foi atendido, o conteúdo recebeu pontuação " $\mathrm{I}$ ". Caso contrário, pontuação "o".

O esquema apresentado na Figura isintetiza as etapas que guiaram o processo para avaliação dos conteúdos das universidades da amostra:

Figura1 Etapas do processo de avaliação dos conteúdos

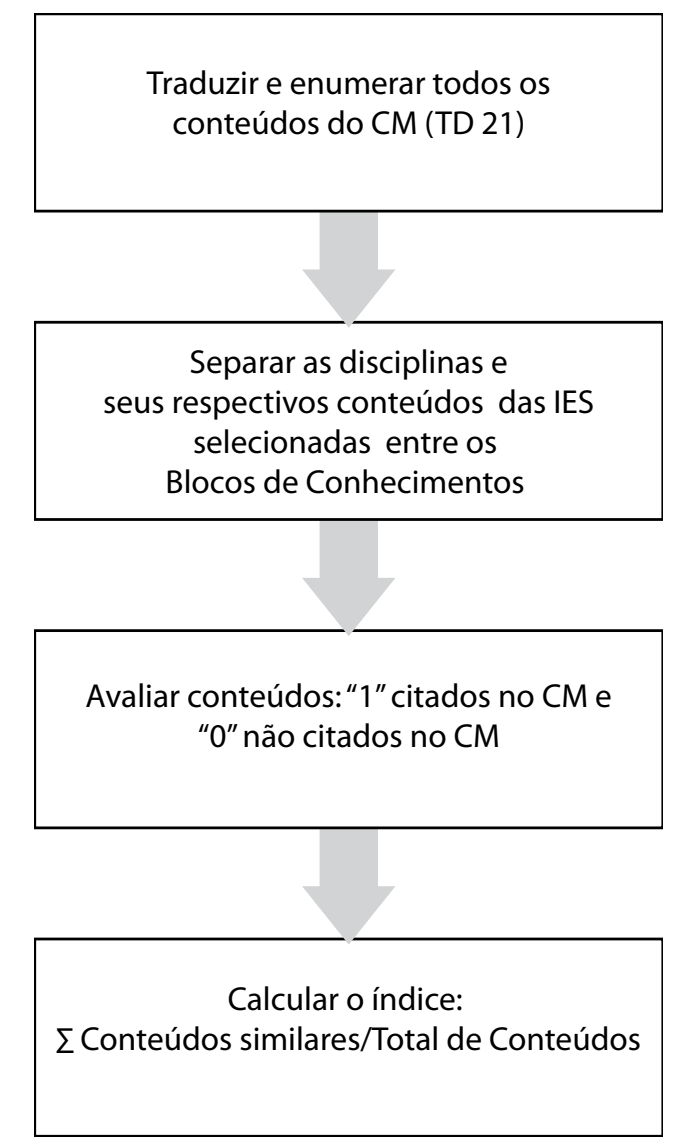

Cabe ressaltar que muitos conteúdos são descritos no $\mathrm{CM}$ de forma generalizada, enquanto nos currículos examinados, tais conteúdos são mais específicos. Neste caso, todos os conteúdos que estivessem de acordo 
com о см, ainda que apresentados de forma concisa, foram analisados e considerados como atendidos Além disso, os conteúdos das IEs foram analisados separadamente, considerando, apenas quando necessário, o bloco de conhecimento a que ele pertencia. Assim, um conteúdo do $\mathrm{cm}$ pertencente ao Bloco I, referente a "Conhecimentos da organização e atividade comercial", por exemplo, foi usado como referência para conteúdos sobre contabilidade, presentes no Bloco 3 das IEs. Além disso, um mesmo conteúdo do $\mathrm{CM}$ foi empregado para diferentes conteúdos das universidades avaliadas.

Já os conteúdos das disciplinas optativas dos currículos mineiros foram confrontados com o quarto bloco de conhecimento proposto pela ONU/ UNCTAD/ISAR, que se refere ao Nível Optativo (Avançado) de Contabilidade, Finanças e Conhecimentos Afins. Como o см designa este bloco como um nível optativo, considerou-se, nesta pesquisa, que as universidades poderiam ou não adotá-lo. Por isso, seus conteúdos foram confrontados com os conteúdos das disciplinas optativas das universidades mineiras estudas. $\mathrm{O}$ quarto bloco propõe um total de 157 conteúdos, divididos em seis módulos, mais um módulo específico sobre estágio.

Observa-se que о см propõe que os conteúdos relativos à contabilidade estejam de acordo com as IAS e IFRs. Contudo, as universidades analisadas não mencionam em seus currículos se as normas internacionais estão sendo adotadas ou não durante o curso. Desta forma, pressupõe-se que, com a aprovação da Lei II.638 e dos CPC's referentes aos assuntos, as instituições de ensino da amostra estão adaptadas a essas novas regras e adequaram suas ementas na sala de aula. Por esta razão, a presente pesquisa analisou como atendidos todos os conteúdos vinculados à contabilidade e às novas normas contábeis, que foram citadas nо см.

Além disso, como о см não define cargas horárias, mantendo esta função ao encargo das instituições de ensino, nesta pesquisa, também não foram consideradas as cargas horárias das universidades analisadas.

Vale ressaltar que esse estudo se depara com algumas limitações. Em primeiro lugar, limitou-se a considerar apenas as ementas ou os programas curriculares das universidades federais mineiras. Os objetivos de cada 
curso, a infraestrutura das universidades e os aspectos culturais, políticos e socioeconômicos, em que cada universidade está inserida, não foram objeto de pesquisa. Logo, não há como avaliar a qualidade dos cursos examinados.

Segundo, verificou-se com a pesquisa que não há um padrão de estrutura e apresentação dos programas curriculares divulgados pelas universidades, ou seja, cada IEs exibe seus conteúdos de maneira diferenciada, alguns mais detalhados do que outros. Desse modo, duas instituições da amostra (UFSJ e UFVJM) divulgaram seus conteúdos por meio de ementas, com os conteúdos apresentados de forma mais sintetizada. Já as outras duas instituições disponibilizaram seus programas curriculares, ou seja, apresentaram seus conteúdos de forma mais detalhada. Embora apresentassem quantidades de conteúdos distintas, e, em alguns casos, de modo mais resumidas que outras, considera-se que a análise dos itens não foi prejudicada.

Terceiro, como não foram realizadas entrevistas com os coordenadores dos cursos analisados ou com os professores destas universidades, para verificar o que é efetivamente ministrado nas salas de aulas, considera-se como uma limitação o fato de algumas universidades, ainda que não tenham especificado determinados conteúdos em suas ementas ou programas, estejam oferecendo determinados assuntos, sugeridos no см. Contudo, a qualidade de ensino dessas universidades não está associada maior ou menor adesão à proposta do CM. Como a própria ONU/UNCTAD/ISAR salienta, por meio do TD 6, cada país que se basear na proposta do CM para a construção de seus programas, deve adequar seus conteúdos às suas necessidades e características locais. Ademais, como mencionado anteriormente, outros fatores também influenciam a qualidade do ensino, como a infraestrutura da instituição, as características culturais e socioeconômicas, bem como as necessidades do mercado de trabalho. 


\section{ANÁLISE DOS DADOS}

Os autores da presente pesquisa dividiram todas as disciplinas obrigatórias dos currículos analisados entre os três blocos de conhecimento propostos pelo см, observando a qual bloco a disciplina se adequava. Já as disciplinas optativas foram alocadas no quarto bloco. Esta distribuição foi realizada com o intuito de analisar as semelhanças e diferenças dos conteúdos das universidades mineiras, com о см por bloco de conhecimento. Ressalta-se que, para alocar as disciplinas aos blocos de conhecimento, considerou-se apenas o assunto que ela aborda (administração, economia, informática e contabilidade e afins) e não se estavam de acordo com os módulos propostos pelo см. Esta análise detalhada ocorreu posteriormente, com a avaliação dos conteúdos. Assim, as disciplinas relacionadas à administração, economia, matemática e estatística foram alocadas no Bloco I, disciplinas referentes à Tecnologia da Informação no Bloco 2, as associadas à Contabilidade e afins (Direito e Finanças) no Bloco 3 e todas as optativas no Bloco 4.

A ufmg oferece, em seu curso de Ciências Contábeis, 40 disciplinas obrigatórias e 47 optativas. Os conteúdos da UFMG foram analisados por meio das ementas e dos programas curriculares, de acordo com a disponibilidade de cada um no sítio eletrônico da respectiva instituição. Ao analisar os conteúdos do curso noturno de contabilidade da UFMG, verificou-se que, entre as disciplinas obrigatórias, são distribuídos 686 conteúdos. E entre as disciplinas optativas 366 .

Na UFS, o curso de contabilidade abrange 4I disciplinas obrigatórias e seis optativas. O programa curricular do curso desta instituição disponibiliza 304 conteúdos entre as disciplinas obrigatórias e 49 conteúdos entre as optativas. Já a UFU fornece, no seu curso, 45 disciplinas obrigatórias e I2 optativas. De acordo com seu programa curricular, há 900 conteúdos distribuídos entre as disciplinas obrigatórias e 240 conteúdos entre as optativas, um total de iı4o conteúdos. Por fim, o curso de Contabilidade da UFVJM contém 4I disciplinas obrigatórias e I4 optativas. Entre as disciplinas obrigatórias, há 205 conteúdos, e I05 entre as optativas. 
O Quadro 4, a seguir, registra a quantidade de conteúdos, obrigatórios e optativos, analisados em cada instituição.

Quadro 4 Quantidade de conteúdos analisados

\begin{tabular}{|llll|}
\hline Universidades & $\begin{array}{l}\text { Conteúdos: } \\
\text { disciplinas obrigatórias }\end{array}$ & $\begin{array}{l}\text { Conteúdos: } \\
\text { disciplinas optativas }\end{array}$ & Total \\
\hline UFMG & 686 & 366 & 1052 \\
\hline UFSJ & 304 & 49 & 353 \\
\hline UFU & 900 & 240 & 1140 \\
\hline UFVJM & 205 & 105 & 310 \\
\hline
\end{tabular}

Como já mencionado anteriormente, um índice de similaridade foi calculado com base na soma da pontuação atingida pela universidade (soma dos conteúdos semelhantes ao proposto pelo $\mathrm{CM}$ ), dividida pelo total de conteúdos que cada instituição de ensino oferece. Desta forma, obtevese, nesta pesquisa, um índice que avalia o grau de semelhança e diferença entre os conteúdos das instituições da amostra e o cM.

O Gráfico I apresenta o índice de similaridade entre conteúdos do $\mathrm{CM}$ com os conteúdos da ementa da UFMG, por bloco de conhecimento. Entre os I.052 conteúdos, 528 são compatíveis aos propostos pela ONU/UNCTAD/ISAR.

Gráfico I Índice de Similaridade entre Currículo UFMG e CM

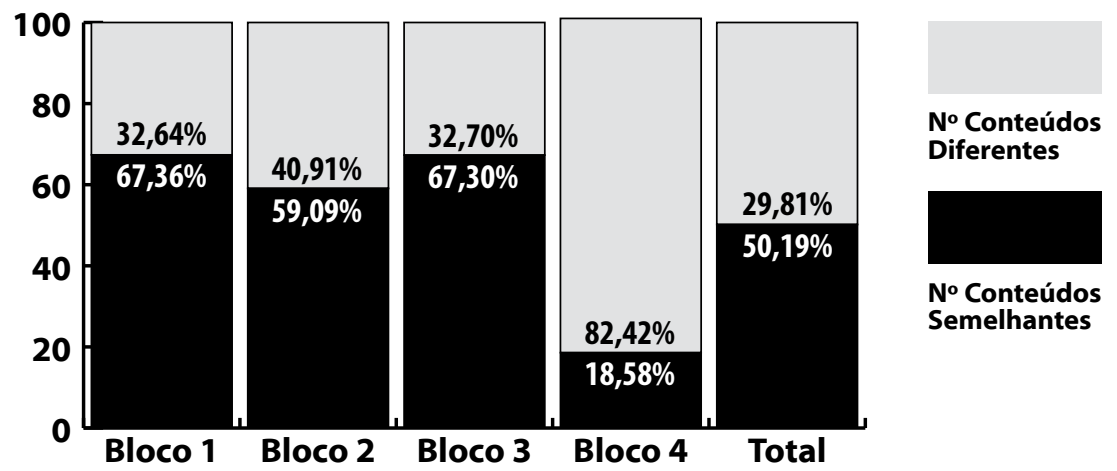


Conforme o Gráfico I, os Blocos I e 3, referentes a Conhecimentos da Organização e Atividade Comercial e Conhecimentos Básicos de Contabilidade e Afins, respectivamente, exibiram pouca variação entre eles, com diferença de 0,06 pontos percentuais. Estes dados mostram que mais de $60 \%$ dos conteúdos ministrados nessa instituição, referentes à administração, economia, matemática, estatística, contabilidade e afins estão coerentes aos propostos pelo cM. Já no bloco 4, o Nível optativo de Contabilidade, Finanças e Conhecimentos Afins (avançados) registrou o menor índice, com apenas I8,58\% de semelhança com o cM. Um dos motivos para esse resultado consiste no fato de que vários conteúdos presentes nas disciplinas optativas são citados nos blocos I, 2 e 3 do см. Porém, como esta pesquisa optou por comparar as disciplinas optativas apenas com o bloco 4, o número de possíveis comparações diminuiu. No total, considerando todos os conteúdos propostos na ementa da UFMG, 50,19\% estão de acordo com o CM.

A UFS apresenta um total de 353 conteúdos em seu programa curricular. Entre estes, 246 estão compatíveis com as propostas do cM. O Gráfico 2, a seguir, expõe o nível de similaridade entre conteúdos do см com os conteúdos da UFSJ.

Gráfico 2 Índice de Similaridade entre Currículo ufsJ e cм
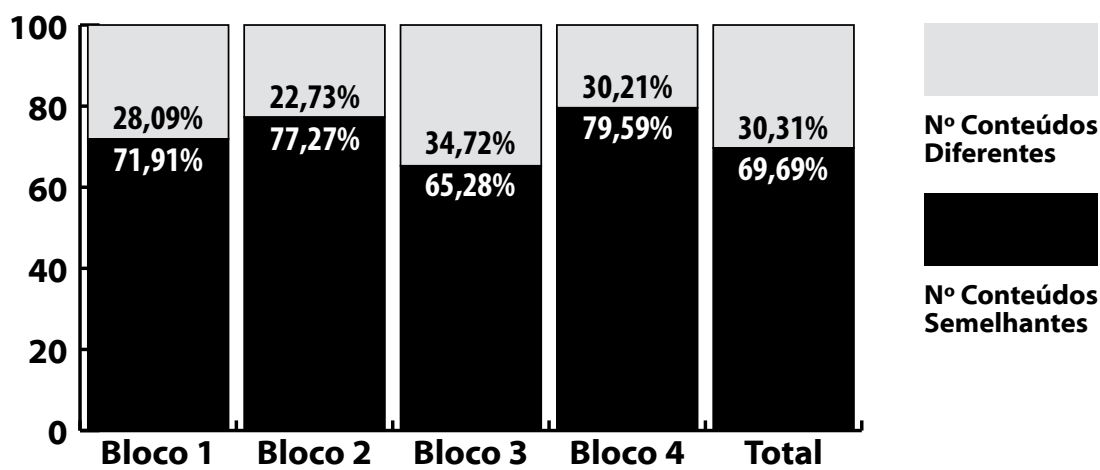
Observa-se, no Gráfico 2, que o Bloco 4, concernente às disciplinas optativas, é o que mais se assemelha com um índice de $79,59 \%$. O fato de a UFSJ disponibilizar poucas disciplinas optativas, em relação às outras universidades analisadas, e a maioria destas disciplinas se reportarem a assuntos de contabilidade, contribuiu para esse resultado. Já o Bloco 2, referente à Tecnologia da Informação, é o segundo grupo que mais se destaca, com um índice de $77,27 \%$ de semelhança. Entretanto isso não quer dizer que as disciplinas de tecnologia da informação da UFS abrangem todos os conteúdos propostos pelo $\mathrm{CM}$. Ao contrário, há muitos conteúdos sugeridos pela ONU que não são ministrados nas salas de aulas da UFSJ, como "Gestão da adoção, aplicação e utilização da tecnologia da informação" e "Gestão da segurança da informação". No total, ao analisar todos os conteúdos, 69,69\% do currículo da uFsJ estão de acordo com o cм.

O currículo da UFU disponibiliza, nos programas curriculares das disciplinas, um total de I.I40 conteúdos. Destes, 675 são semelhantes ao CM. A seguir, o Gráfico 3 exibe o índice de similaridade entre os conteúdos da UFU com o см por bloco de conhecimento.

Gráfico 3 Índice de Similaridade entre Currículo Ufu e CM

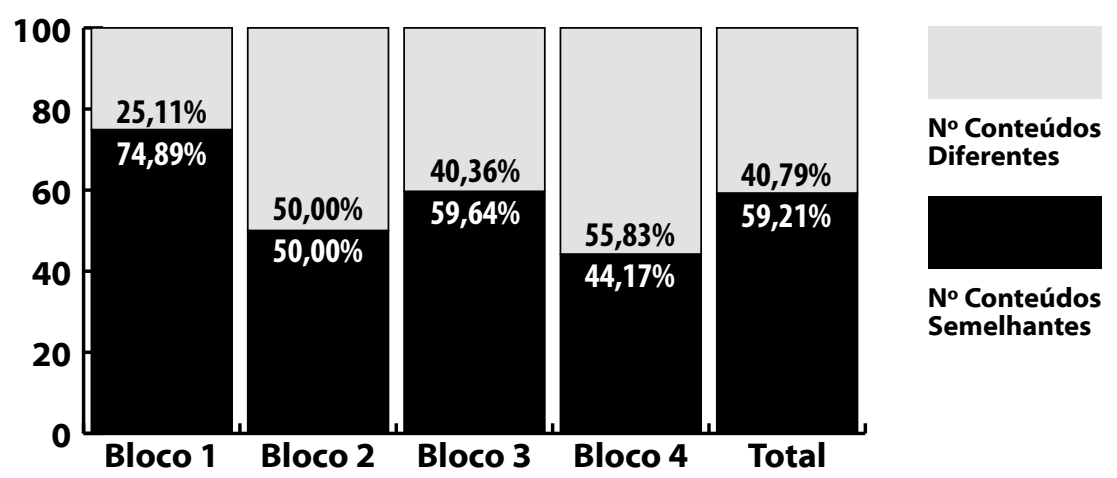


Observa-se, no Gráfico 3, que o Bloco r é o que apresenta maior similaridade entre conteúdos da UFu com o cM, com índice de 74,89\%. Em seguida, o Bloco 3, sobre contabilidade e afins, com 59,64\%. O Bloco 4, com os conteúdos das disciplinas optativas, se assemelha em 44,I7\% com o CM. Conclui-se, deste modo, que 59,2I\% dos II 40 conteúdos da UFU estão de acordo com a proposta de unificação de currículos da ONU/UNCTAD/ISAR.

Finalmente, a ufvJM mostra um índice total de similaridade com о см de 51,61\%, ou seja, dos 310 conteúdos oferecidos pela instituição I60 são similares ao см. O Gráfico 4, a seguir, expõe o grau de semelhança por bloco de conhecimento:

Gráfico 4 Índice de Similaridade entre Currículo ufvjm e см

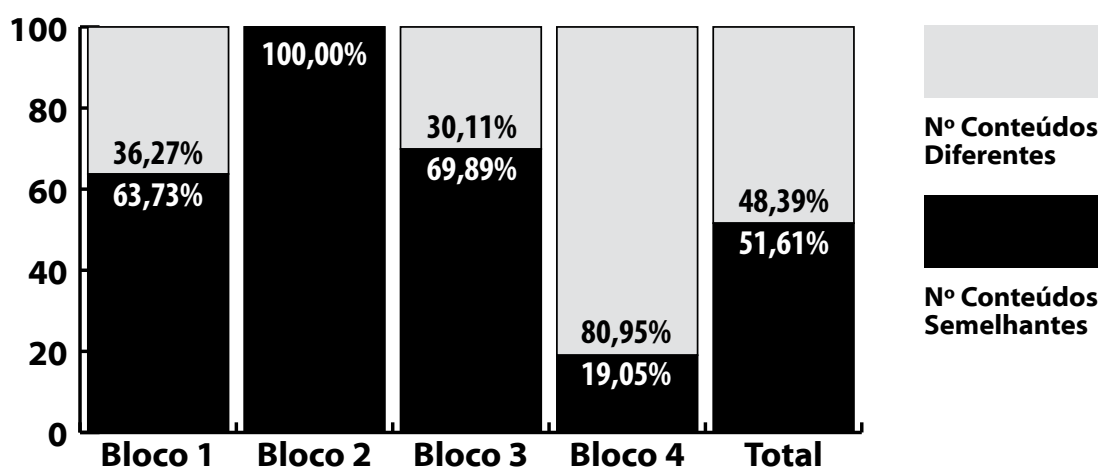

Por meio do Gráfico 4, é possível verificar que o Bloco 2, relativo à disciplina de Tecnologia da Informação, registra 100\% de semelhança com o cM. Este índice demonstra que todos os conteúdos concernentes a este assunto, oferecidos pela UfvJM, foram sugeridos pela onU. Contudo, assim como a UFS, isso não denota que estas disciplinas não estão isentas de reavaliação, pois há vários conteúdos propostos pelo cm que não são lecionados nessa instituição, como "Gestão da aquisição, desenvolvimento e aplicação de sistemas", "Comércio eletrônico" e "Controle financeiro da tecnologia da informação". 
Em contrapartida, o Bloco 4, composto pelas disciplinas optativas, mostra apenas $19,05 \%$ de semelhança com o CM. Isto ocorre porque a maioria das disciplinas optativas desta universidade foi sugerida nos primeiros blocos de conhecimento, principalmente em assuntos relativos à Administração de Empresas e, por isso, não foram comparadas.

Para melhor visualizar o índice de similaridade calculado para cada universidade, o Gráfico 5 exibe o valor total que cada instituição alcançou.

Gráfico 5 Índice de Similaridade entre Universidades com CM

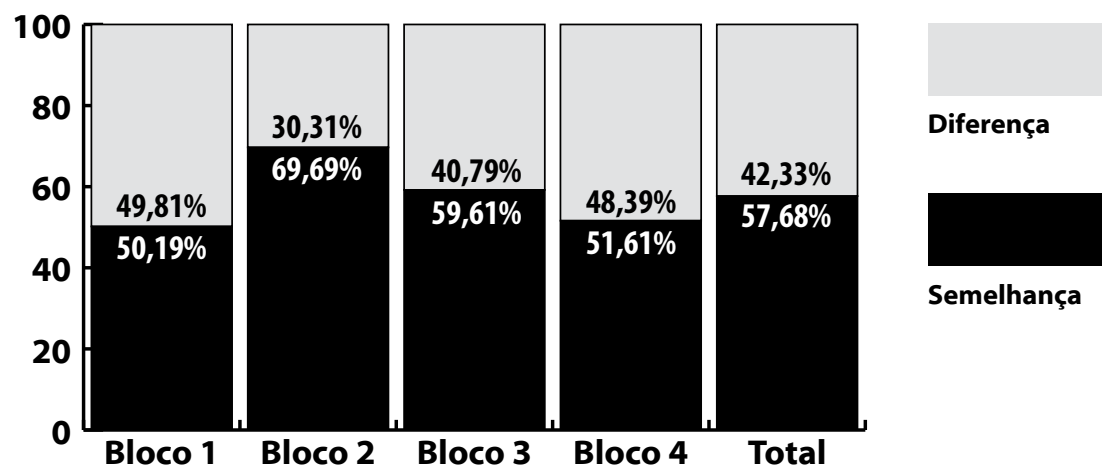

Com base no Gráfico 5, observa-se que a instituição de ensino que possui o currículo mais semelhante ao см é a UFSJ, com índice de 69,69\%. Em seguida, a UFU, com 59,21\%. A variação entre as quatro universidades é de 19,5 pontos percentuais, e a média de similaridade, entre as instituições analisadas, com о см é de 57,68\%. Estes dados foram calculados com base na análise de todos os conteúdos presentes nos currículos das universidades selecionadas. Porém, se a análise considerar apenas os conteúdos das disciplinas obrigatórias, obtêm-se índices diferentes, conforme o Gráfico 6, a seguir: 
Gráfico 6 Índice de Similaridade entre Universidades Mineiras com cм: análise das disciplinas obrigatórias

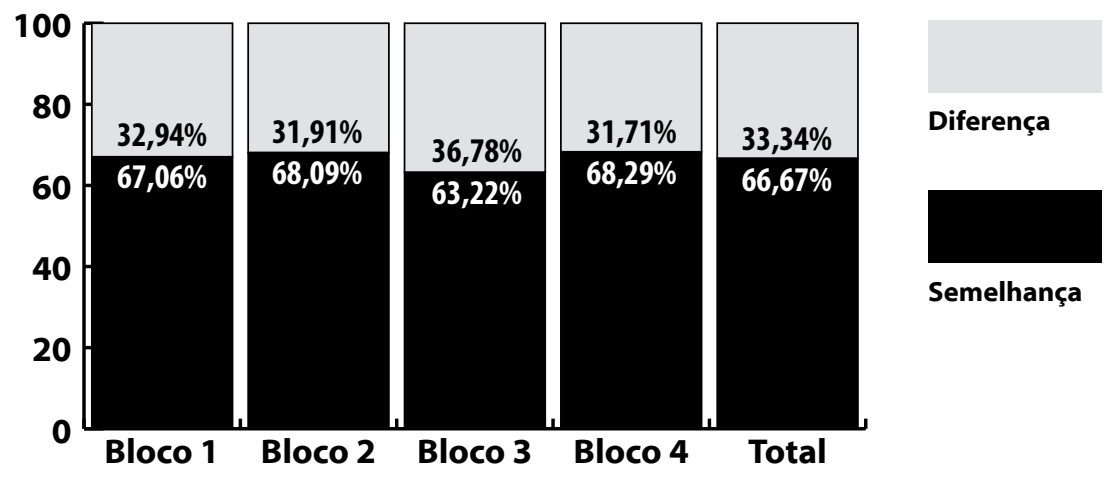

Segundo esses dados, (Gráfico 6), a ufVJM é a instituição com maior semelhança com o cM, com índice de $68,29 \%$ e não a UFSJ, que se configura na segunda posição, com $68,09 \%$. A variação do maior valor para o menor, entre as quatro universidades, também diminui para 5,07 pontos percentuais, enquanto a média aumenta para $66,67 \%$.

O Quadro 5 expõe, de forma resumida, a análise aqui apresentada, com os índices de similaridade registrados por cada instituição e por Bloco de Conhecimento.

Quadro 5 índices de similaridade registrados por cada IEs e por Bloco de Conhecimento

\begin{tabular}{|lllllll|}
\hline Instituição & Bloco 1 & Bloco 2 & Bloco 3 & Bloco 4 & $\begin{array}{l}\text { Total } \\
\text { Conteúdos }\end{array}$ & Similaridade \\
\hline UFMG & $67,36 \%$ & $59,09 \%$ & $67,30 \%$ & $18,58 \%$ & 1052 & $50,19 \%$ \\
\hline UFS & $71,91 \%$ & $77,27 \%$ & $63,28 \%$ & $79,59 \%$ & 353 & $69,69 \%$ \\
\hline UFU & $74,89 \%$ & $50 \%$ & $59,64 \%$ & $44,17 \%$ & 1140 & $59,21 \%$ \\
\hline UFVJM & $63,73 \%$ & $100 \%$ & $69,89 \%$ & $19,05 \%$ & 310 & $51,61 \%$ \\
\hline
\end{tabular}




\section{RESULTADOS DE PESQUISAS ANTERIORES}

Entre as pesquisas apresentadas no Quadro 2, seis artigos apresentaram análise quantitativa, nos quais foram registrados o percentual de similaridade entre o CM e as IES selecionadas, que ofertam graduação em Ciências Contábeis. O Quadro 6, a seguir, apresenta o resultado das pesquisas que forneceram o percentual de semelhança entre o см e as disciplinas das IES pesquisadas.

Quadro 6 Pesquisas que apresentaram percentual de semelhança entre CM e IEs pesquisadas

\begin{tabular}{|c|c|c|}
\hline Autores & IES selecionadas & Similaridade (média) \\
\hline Magalhães e Andrade (2006) & $\begin{array}{l}20 \text { cursos de Ciências } \\
\text { Contábeis do Estado do Piauí }\end{array}$ & $60 \%$ \\
\hline $\begin{array}{l}\text { Czesnat, Cunha e Domingues } \\
\text { (2009) }\end{array}$ & $\begin{array}{l}12 \text { universidades de Santa } \\
\text { Catarina }\end{array}$ & $88,27 \%$ \\
\hline Segantini et al. (2010) & 4 universidades do MERCOSUL & $76,71 \%$ \\
\hline Cavalcante et al. (2011) & $\begin{array}{l}27 \text { universidades federais } \\
\text { brasileiras }\end{array}$ & Menos de $50 \%$ \\
\hline $\begin{array}{l}\text { Zonatto, Dani e Domingues } \\
\text { (2011) }\end{array}$ & $\begin{array}{l}51 \text { IES listadas pelo MEC do Rio } \\
\text { Grande do Sul (RS) }\end{array}$ & $91,73 \%$ \\
\hline $\begin{array}{l}\text { Santos, Domingues e Ribeiro } \\
\text { (2011) }\end{array}$ & 72 IES do estado do Paraná & $\begin{array}{l}88,38 \% \text { (IES públicas: } 90,36 \% \\
\text { e IES privadas: } 87,86 \% \text { ) }\end{array}$ \\
\hline
\end{tabular}

Verifica-se que variação dos resultados encontrados entre as pesquisas citadas no Quadro 6, é relativamente alta, apesar das diferentes amostras e métodos utilizados. Essas pesquisas se assemelham ao comparar apenas as disciplinas do CM com as disciplinas das IEs selecionadas, ao contrário do presente estudo, que comparou os conteúdos do см com os conteúdos sugeridos pelas universidades federais do estado de Minas Gerais. Além disso, as pesquisas não consideraram as disciplinas optativas na análise comparativa, exceto Magalhães e Andrade (2006) e Cavalcante et al. (20II), que não mencionam se as optativas foram consideradas ou não em suas análises.

Outro fator que merece ser destacado refere-se ao documento utilizado como referência para as comparações. Magalhães e Andrade (2006), Czesnat, 
Cunha e Domingues (2009), Zonatto, Dani e Domingues (20II) e Santos, Domingues e Ribeiro (20II) seguem o modelo de Riccio e Sakata (2004), os quais apresentam os Blocos de Conhecimento ( $\mathrm{I}, 2$ e 3 ) citados no TD6 mais um quarto bloco, denominado de Conhecimentos Gerais, o qual foi adaptado pelos respectivos autores. Segantini et al. (2010) fundamenta sua análise mediante o documento revisado TD 2I, sugerido pela ONU/UNCTAD/ ISAR, do mesmo modo que a presente pesquisa. Já Cavalcante et al. (20II) apoiam sua pesquisa seguindo o modelo apresentado por de Riccio e Sakata (2004), e consideram também o quarto Bloco, sugerido pelo TD 2I, referente ao Bloco optativo avançado em contabilidade. O fato de apresentarem diferentes bases de comparação (TD 6 mais bloco de Conhecimentos Gerais e TD 2I) pode ser um dos motivos pela variação entre os resultados das pesquisas sobre análises comparativas.

Os resultados da presente pesquisa, a qual constatou que a semelhança entre as universidades federais do estado de Minas Gerais e o см é de 66,67\% se considerados apenas os conteúdos obrigatórios, e 57,68\% se considerados conteúdos obrigatórios e optativos, são mais próximos dos resultados apresentados por Cavalcante et al. (20II), o qual registrou que a semelhança entre as grades curriculares das universidades federais brasileiras е о см é menor que $50 \%$. Essa diferença pode ser explicada pelo fato de a primeira pesquisa ter comparado todos os conteúdos adotados pelas IES selecionadas, e não apenas as disciplinas, o que permitiu uma maior abrangência da proposta dо см е das universidades pesquisadas.

Em contrapartida, os índices registrados pela presente pesquisa se distanciaram do resultado da pesquisa de Santos, Domingues e Ribeiro (20II), os quais verificaram que as disciplinas das IES públicas do estado do Paraná são 90,36\% semelhantes às disciplinas do CM. 


\section{CONSIDERAÇÕES FINAIS}

Este trabalho teve por objetivo analisar o Currículo Mundial (см) desenvolvido e recomendado pelo ONU /UNCTAD/ISAR e compará-lo com o adotado por universidades federais mineiras, com o intuito de identificar as similaridades e diferenças e apresentar, quantitativamente, o nível de semelhança entre o cm e os currículos mineiros analisados.

Foram selecionados quatro currículos de universidades federais para o estudo, com base na divulgação do currículo e das ementas nas respectivas homepages e no fornecimento do material via email. Foram eles: a UFMG, a UFSJ, a UfU e a UFVJM. Um índice foi calculado para cada instituição, o qual avalia a similaridade entre os currículos das universidades analisadas com a proposta da ONU. Para calcular o índice, cada conteúdo das universidades mineiras recebeu uma nota: "I" para os conteúdos indicados pelo cM, e "o" para os que não foram indicados. O somatório alcançado por cada instituição foi dividido pela pontuação máxima que cada universidade poderia alcançar. Desta forma, o resultado obtido permitiu avaliar cada currículo proposto pelas instituições de ensino e compará-lo com o sugerido pelo cM.

Verificou-se que a UFMG tem um percentual de atendimento de 50,19\%, com as principais diferenças nos conteúdos relacionados ao Bloco 4 , das disciplinas optativas. No currículo da UFSJ, foi detectado que $69,69 \%$ dos conteúdos estão de acordo com o cM, com o maior descumprimento relacionado ao Bloco 3, sobre Contabilidade e Afins. Essa universidade foi a que apresentou maior similaridade entre as quatro da amostra, em relação ao см. Para a Ufu, observou-se que 59,2I\% de seu currículo é semelhante ao currículo desenvolvido pela ONU/UNCTAD/ISAR. O bloco 4, das disciplinas optativas, seguido do bloco 2, sobre Tecnologia da Informação, foram os que exibiram menor índice de similaridade. Já a ufvJм registrou um índice de 51,61\% de semelhança com o см. O menor índice foi representado pelo Bloco 4, das disciplinas optativas, e o maior, no Bloco 2, sobre Tecnologia da Informação.

Entretanto, ao considerar apenas os conteúdos das disciplinas obrigatórias na análise, observou-se que os índices calculados foram bem maiores. Neste 
caso, a UfvJM revelou-se a instituição com maior semelhança com o CM, com índice de $68,29 \%$, a ufSJ com $68,09 \%$, a UFMG com $67,06 \%$ e a UFu com $63,22 \%$. A variação entre as quatro universidades diminuiu para 5,07 pontos percentuais, enquanto a média aumentou para $66,67 \%$. Estes resultados mostram que os índices de similaridades entre as universidades mineiras e o cM são próximos, com pouca variação, se analisadas apenas as disciplinas obrigatórias. Conclui-se que o que acentua a diferença entre os currículos das instituições mineiras, comparados com o CM, são os conteúdos das disciplinas optativas.

Este estudo limitou-se a considerar apenas as ementas e/ou os programas curriculares das universidades federais mineiras. Sugere-se, então, que os próximos trabalhos sobre o assunto ampliem a amostra, incluindo outras instituições de ensino de contabilidade, e que também que se aprofundem no estudo, de forma a analisar os principais conteúdos do CM que não são adotados pelas universidades brasileiras.

Podem-se destacar algumas limitações observadas nesse estudo. Em primeiro lugar, este estudo limitou-se a considerar apenas as ementas ou os programas curriculares das universidades federais mineiras. Outros fatores que interferem na qualidade do ensino, como a cultura, o aspecto socioeconômico ou social não foram objeto de estudo da pesquisa. Por isso, não se pode avaliar a qualidade de ensino dos cursos examinados. Em segundo, não há um padrão de estrutura e apresentação dos programas curriculares divulgados pelas universidades, ou seja, cada IEs exibe seus conteúdos, por meio dos programas ou ementas, de maneira diferenciada, alguns mais detalhados do que os outros. Por fim, algumas universidades, podem lecionar determinados assuntos, sugeridos no $\mathrm{CM}$, na sala de aula, ainda que esses não estejam especificados em suas ementas ou programas. Entretanto, o estudo restringiu-se a coletar apenas os conteúdos disponibilizados pelas instituições, e não verificou, com isso, o que, de fato, é ministrado nas salas de aulas. 
Como isso, sugere-se, para próximas pesquisas sobre análise comparativa com o см avaliar, não apenas os conteúdos das disciplinas lecionadas nas IES, mas também a percepção dos coordenadores dos cursos, bem como a experiência dos professores em relação à adoção da proposta da ONU/ UNCTAD/ISAR. 


\section{REFERENNCIAS}

ANDRADE, M. M. de. Introdução à Metodologia do Trabalho Científico. 6. ed. São Paulo: Atlas, 2002.

ASHCROFT, P.; CHEVIS, G.; SMITH, L. M. Faculty perspectives on international accounting topics. Advances in Accounting, incorporating Advances in International Accounting, v. 24, p. 139-144, 2008. Disponível em:

<http://www.sciencedirect.com/science/article/pii/S088261100800014X > . Acesso em: 15/04/2011.

BEUREN, I.M. (Org.). Como elaborar trabalhos monográficos em Contabilidade. São Paulo: Atlas, 2006.

BRASIL. LEI N ${ }^{\circ}$ 9.394, DE 20 DE DEZEMBRO DE 1996. Estabelece as diretrizes e bases da educação nacional. Brasília, 2006. Disponível em: <http://www.planalto.gov.br/ ccivil_03/Leis/L9394.htm.>. Acesso em: 17/03/2011.

BRASIL. LEI N ${ }^{\circ} 11.638$, DE 28 DE DEZEMBRO DE 2007. Altera e revoga dispositivos da Lei no 6.404, de 15 de dezembro de 1976, e da Lei no 6.385, de 7 de dezembro de 1976, e estende às sociedades de grande porte disposições relativas à elaboração e divulgação de demonstrações financeiras. Brasília, 2007. Disponível em:

<http://www.planalto.gov.br/ccivil_03/_ato2007-2010/2007/lei/l11638.htm>. Acesso em: 17/03/2011.

CAVALCANTE, D. S.; AQUINO, L. D. P. de; LUCA, M. M. M. de; PONTE, V. M. R.; BUGARIM, M. C. C. Adequação dos Currículos dos Cursos de Contabilidade das Universidades Federais Brasileiras ao Currículo Mundial de Contabilidade e o Desempenho no Enade. Pensar Contábil, Rio de Janeiro, v. 13, n. 50, p. 42 - 52, jan./abr. 2011.

COMITE DE PRONUNCIAMENTOS CONTÁBEIS. Conheça o CPC. Disponível em: $<$ http://www.cpc.org.br/oque.htm>. Acesso em: 17/03/2011.

CONSELHO FEDERAL DE EDUCAÇÃO. Resolução no 3, de 5 de outubro de 1992. Fixa os mínimos de Conteúdos e duração do curso de graduação em Ciências Contábeis. Disponível em: <http://www.humbertorosa.com.br/Coordenacao/ Legislacao\%20do\%20Curso/01_Resolucao_CFE_03_1992.pdf>. Acesso em: 17/03/2011 CONSELHO NACIONAL DE EDUCAÇÃO. Resolução CNE/CES 10, de 16 de dezembro de 2004. Institui as Diretrizes Curriculares Nacionais para o Curso de Graduação em Ciências Contábeis, bacharelado, e dá outras providências. Disponível em: $<$ http:// r1.ufrrj.br/graduacao/arquivos/docs_diretrizes/cconrces10_04_resol.pdf $>$. Acesso em: 17/03/2011.

CZESNAT, A. F.O.; CUNHA, J.V.A. Uma análise comparativa entre os currículos dos cursos de ciências contábeis das universidades do estado de Santa Catarina listadas no MEC com o currículo internacional proposto pela UNCTAC/ONU/ISAR. In: SEMEAD - Seminários em Administração, 12., 2009, Santa Catarina. Anais... Santa Catarina, 2009. 
CZESNAT, A. F. O; CUNHA, J. V. A.; DOMINGUES, M.J.C.S. Análise comparativa entre os currículos dos cursos de ciências contábeis das universidades do estado de santa Catarina listadas pelo MEC e o currículo mundial proposto pela ONU/ UNCTAD/ISAR. Gestão \& Regionalidade, v. 25, n. 75, p.22-30, set./dez. 2009.

DUTRA, O.T. Proposta de uma matriz curricular para o curso de Ciências Contábeis na grande Florianópolis. São Paulo, 2003. 151 f. Dissertação (Mestrado em Contabilidade e Controladoria) - Faculdade de Economia, Administração e Contabilidade da Universidade de São Paulo, São Paulo.

ERFURTH, A.E.; DOMINGUES, M.J.C.S. Estrutura curricular do curso de ciências contábeis na universidade de Buenos Aires versus a estrutura curricular proposta pelo ISAR/UNCTAD. In: SEMINÁRIO DE CIÊNCIAS CONTÁBEIS FURB, 4., 2008, Blumenau, Anais... Disponível em: <https://www.furb.br/especiais/ download/714416-763114/CCG0262008.pdf>. Acesso em: 08/11/2010.

ECHTERNACHT, T.H.de S. O ensino da Contabilidade Internacional nos cursos de graduação em Ciências Contábeis Do Brasil. João Pessoa, 2006. 93 f. Dissertação (Mestrado em Ciências Contábeis) Programa Multiinstitucional e Inter-Regional de PósGraduação em Ciências Contábeis da UnB, UFPB, UFPE e UFRN.

GIL, A.C. Como elaborar projetos de pesquisa. 4. ed. São Paulo: Atlas, 2006.

GUBIANI, A.C.; SANTOS, V. dos; KLANN, R.C.; FILHO, J.R.T. Disclosure dos derivativos nas notas explicativas das empresas dos segmentos de papel e celulose e de carnes e derivados. In: SEMEAD - SEMINÁRIOS EM ADMINISTRAÇÃO, 13., 2010, Anais... São Paulo, 2010.

KAVANAGH, M.H.; DRENNAH, L. What skills and attributes does an accounting graduate need? Evidence from student perceptions and employer expectations. Accounting \& Finance, 2007, v. 48, p. 279-300. Disponível em: <http://migre. me/1cKUm>. Acesso em: 15/04/2011.

LAKATOS, E.M.; MARCONI, M.de A. Metodologia do trabalho científico: procedimentos básicos, pesquisa bibliográfica, projeto e relatório, publicações e trabalhos científicos. 6 . ed. São Paulo: Atlas, 2001.

LIMA, M.; LEMOS, M. de F.; ANAYA, V. Currículo escolar e construção cultural: uma análise prática. Dialogia, São Paulo, v. 5, p. 145-151, 2006.

LIN, Z. J.; XIONG, X.; LIU, M. Knowledge base and skill development in accounting education: Evidence from China. Journal of Accounting Education. ed. 23, p.149169, 2005. Disponível em: < http://www.sciencedirect.com/science/article/pii/ S0748575105000333> Acesso em: 16/04/2011.

MAGALHÃES, F.AC.; ANDRADE, J.X. A educação contábil no estado do Piauí diante da proposta de convergência internacional do currículo de contabilidade concebida pela ONU/UNCTAD/ISAR. In: CONGRESSO USP CONTROLADORIA E CONTABILIDADE, 6., São Paulo. Anais...São Paulo, 2006. 
MALAQUIAS, R.F. Disclosure de instrumentos financeiros segundo as normas internacionais de contabilidade: evidências empíricas de empresas brasileiras. Uberlândia, 2008. 161f. Dissertação (Mestrado em Administração) - Curso de Pós-Graduação em Administração, Universidade Federal de Uberlândia.

MESSICK, R. G.; PAIXÃO, L.; BASTOS, L. R. (Org.). Currículo: análise e debate. Rio de Janeiro: Zahar Editores, 1980. 162 p.

MULATINHO, C.E.S. Educação Contábil: um estudo comparativo das grades curriculares e da percepção dos docentes dos cursos de graduação das Universidades Federais da Paraíba, Pernambuco e Rio Grande do Norte, referentes ao Programa Mundial de Estudos em Contabilidade proposto pelo ISAR/UNCTAD/ONU. Recife, 2007. 254f. Dissertação (Mestrado em Ciências Contábeis). Programa Multiinstitucional e Inter-regional de Pós-Graduação em Ciências Contábeis da Universidade de Brasília, Universidade Federal da Paraíba, Universidade Federal de Pernambuco e Universidade Federal do Rio Grande do Norte.

PELEIAS, I.R. (Org.). Didática do Ensino da Contabilidade: aplicável a outros cursos superiores. São Paulo: Saraiva, 2006. 348 p.

PEREIRA, D. M. V.G.; LOPES, J.E.G.; PEDERNEIRAS, M.M.M.; MULATINHO, C.S. A formação e a qualificação do contador face ao programa Mundial de estudos em contabilidade proposto pelo ISAR: uma Abordagem no processo ensino-aprendizagem. In: CONGRESSO USP INICIAÇÃO CIENTÍfICA, 2., 2005, São Paulo. Anais...

Disponível em: <http://www.congressousp.fipecafi.org/artigos22005/192.pdf>. Acesso em: 08/11/2010.

PIRES, C.B.; OTT, E. Estrutura curricular do curso de Ciências Contábeis no Brasil versus Estruturas curriculares propostas por organismos internacionais. In: CONGRESSO USP de CONTROLADORIA E CONTABILIDADE, 8., 2008, São Paulo. Anais...

PREOBRAGENSKAYA, G.G.; MCGEE, R.W. Reforming the accounting curriculum in Russia: some guidelines based on the Armenian and Bosnian experiences. Andreas School of Business Working Paper Series 2002. Disponível em:

< http://papers.ssrn.com/sol3/papers.cfm?abstract_id=410766 > . Acesso em: 15/04/2011.

RICCIO, E.L.; SAKATA, M.C.G. Evidências da globalização na educação contábil: estudo das grades curriculares dos cursos de graduação em universidades brasileiras e portuguesas. Revista Contabilidade \& Finanças, n. 35, p. 35-44, 2004.

SACRISTÁN, J.C. O currículo: uma reflexão sobre a prática. Tradução de Ernani F. da F. Rosa. 3 ed. Porto Alegre: ArtMed, 2000. 352 p.

SANTOS, A.C.; DOMINGUES, M.J.C.S.; RIBEIRO, M.J. Um estudo sobre o nível de aderência dos cursos de Ciências Contábeis das Instituições paranaenses listadas no MEC, ao Currículo Mundial. In: CONGRESSO DA ANPCONT, 6., Vitória. Anais... Disponível em: < http://www.anpcont.com.br/site/docs/congressoV/EPC085resumo. pdf $>$. Acesso em: 14/04/2011. 
SEGANTINI, G. T.; VIEIRA; E. R. F. C.; MELO, C. L. L.; SILVA, J. D. G. Uma Análise Comparativa entre os currículos dos cursos de Ciências contábeis nos países do MERCOSUL com o currículo internacional proposto pela ONU/UNCTAD/ISAR. In: CONGRESSO USP DE INICIAÇÃO CIENTÍFICA EM CONTABILIDADE, 7., São Paulo. anais...

UNITED NATIONS CONFERENCE ON TRADE AND DEVELOPMENT - UNCTAD. Revised model accounting curriculum (CM). TD/B/COM.2/ISAR/21 (2003). Disponível em: $<$ http://www.unctad.org.> Acesso em: 18/10/2010.

UNITED NATIONS CONFERENCE ON TRADE AND DEVELOPMENT UNCTAD. Guideline for a global accounting curriculum And other qualification requirements. TD/B/COM.2/ISAR/5 (1998). Disponível em: <http://www.unctad.org.> Acesso em: $18 / 10 / 2010$.

UNITED NATIONS CONFERENCE ON TRADE AND DEVELOPMENT - UNCTAD. Global curriculum for the professional education of professional accountants. TD/B/COM.2/ ISAR/6. (1998). Disponível em: <http://www.unctad.org/en/docs/c2isard6.en.pdf >. Acesso em: 18/10/2010.

ZONATTO, V.C. da S; DANI, A.C.; DOMINGUES, M.J.C.S. Análise comparativa entre o currículo mundial proposto pela ONU/UNCTAD/ISAR e os currículos dos Cursos de Graduação presenciais em Ciências Contábeis das Instituições de Ensino Superior do Estado do Rio Grande do Sul listadas pelo MEC. In: CONGRESSO BRASILEIRO DE CUSTOS, 18., Rio de Janeiro. Anais... 


\section{DADOS DOS AUTORES}

\section{LARISSA COUTO CAMPOS^lari.couto@hotmail.com}

Graduanda em Ciências Contábeis pela Universidade Federal de Uberlândia Instituição de vinculação: Universidade Federal de Uberlândia Uberlândia/MG - Brasil

Áreas de interesse em pesquisa: Educação em Contabilidade.

* Endereço: Av. João Naves de Ávila, 2121 Bloco F - Sala 1 F 215

Santa Mônica Uberlândia/MG 38.400-902

†eneficiário de auxílio financeiro da Pró-Reitoria de Graduação da Universidade Federal de Uberlândia.

SIRLEI LEMES sirlemes@uol.com.br

Doutora em Controladoria e Contabilidade Instituição pela FEA/USP

Instituição de vinculação: Universidade Federal de Uberlândia

Uberlândia/MG - Brasil

Áreas de interesse em pesquisa: Contabilidade Internacional e para usuários externos. 